\title{
Web Strategy to Convey Marine Biogeochemical Feedback Concepts to the Policy Community: Aerosol and Sea Ice
}

\author{
Zachary M. Menzo ${ }^{1,2}$ \\ 1 Department of Climate Science and Policy, Scripps Institution of Oceanography, San Diego, CA 92037, USA; \\ zmenzo@ucsd.edu \\ 2 Los Alamos National Laboratory, Los Alamos, NM 87545, USA
}

Received: 25 October 2017; Accepted: 12 January 2018; Published: 16 January 2018

\begin{abstract}
Limited understanding of the climate system imposes upon policy makers an intimate reliance on results from Earth System Models (ESMs). However, climate simulations are necessarily incomplete since many strong channels through planetary scale biology and geochemistry remain too complex or poorly comprehended to include. This paper presents and describes an interactive, public domain website detailing the role of two marine biogeochemical (mBGC) feedback loops currently excluded from many ESMs (www.marinefeedbacks.com). Every page on the website includes images or videos to foster engagement with its technically challenging content. Simultaneously, fundamentals of the natural science involved are reinforced. The site includes subsections of the following nature; background information, executive summaries for each feedback type, detailed descriptions of the chemical mechanisms, climate change impact, and recommendations for future research. The information provided is firmly grounded in the technical literature but is designed specifically for accessibility to non-scientists. Particular targets for the material are the next-generation of decision makers and those framing the international climate agenda. It is hoped that a site with tailored pedagogical value may contribute to well informed policy formulation and legislation.
\end{abstract}

Keywords: dimethyl sulfide; ice chlorophyll; marine biogeochemical feedbacks; climate change; phytoplankton; policy and decision makers; scientific communication

\section{Introduction}

One of the greatest challenges facing next-generation policy and decision makers will be their handling of climate change within the international community. For most participants in the debate, popular understanding of the climate system and its evolution can be summarized by a few buzz words e.g., carbon dioxide, rising sea level, melting ice caps. Ultimately, climate policy experts rely on data provided by Earth system models (ESMs) to conduct their analyses. Even today after decades of development, global climate simulations remain highly incomplete. Important channels are too complicated or poorly understood to recreate in a numerical sense, and this is particularly true where the complexities of biology and chemistry overlap. Their intersection occurs as the discipline of biogeochemistry and it is here that significant deficiencies tend to be found or suspected.

In some cases, the problems can be set aside because the influence on climate may be limited. Ocean systems, however, are vast in their scale and especially understudied [1]. Intricately balanced and interwoven planktonic communities control key marine biogeochemical (mBGC) feedbacks through processes only beginning to be unraveled [2]. Experts are finding that some of the mBGC controls may accelerate global warming, while others have a cooling effect. Omission from ESMs means the impacts are not represented in resulting analyses, perhaps leading to biases in the results. Since no single existing policy has arisen to resolve this problem, new methodologies are clearly needed. 
As a potential (partial) solution, a free and interactive website has been designed familiarizing two specific mBGC feedbacks and their respective roles in the planetary climate system (www. marinefeedbacks.com). The site includes the dimethyl sulfide (DMS) cloud-albedo feedback effect following release of the trace gas by phytoplankton, oxidation to involatile sulfate in the atmosphere, leading to an increase in droplet number concentrations and cloud lifetimes. It also details a strong but underexplored ice chlorophyll feedback which occurs during high latitude spring and summer. Some polar phytoplankton bloom both near and within the sea ice pack, coloring the domain and trapping heat. Surrounding and internal waters are warmed so that the system may be melted from the inside out. Users of the site can also explore relevant concepts at an introductory level, including the broad notion of anthropogenic climate change itself, prospects for various alternative natural feedbacks, and the life cycle of political analyses. Descriptions were written with the non-scientist in mind, with technical concepts carefully explained through clear verbiage, compelling images, and several real-world examples. After its recent inauguration and initial description, the site is meant to serve as a living document which can be continually developed to include additional feedback and future results. In fact, readers of this article are encouraged to make contact and contribute.

The mBGC feedbacks site targets future decision makers and government officials since they are still in formative stages of their careers. During their training period, young professionals in transition are typically seeking to distinguish themselves, perhaps to garner useful letters of recommendation for future employment. They may be tightly focused on generating or absorbing new concepts so that there is a certain openness to extra reading or investigation. Job candidates often report spending additional time focusing on their academic pursuits and research since there could be unexpected benefits down the road [3].

It is difficult to deny that upcoming decision makers will tend to rely on the internet as they find ways to creatively accomplish their professional goals. They will certainly access information by networking on various social media platforms. An approach employed by the website described here is to exploit the time and energy that next generation policy participants are likely to spend online. In fact, Facebook is called upon in order to reach student democratic organizations, for marketing directly to the desired audience.

\section{2. mBGC Feedbacks}

Currently, both the DMS cloud-albedo and ice chlorophyll feedbacks are included on the website. The door is left open for additions by qualified readers at some later date. For example, interest in the role of phyto-generated macromolecules in determining salt spray and organic fluxes has been rising of late $[4,5]$. This section introduces both mBGC processes explained on the site. Emphasis is placed on the sulfur feedback since the project is aerosol-centric, and so keeping with the topic of this special issue. Additional information regarding the ice chlorophyll loop may be found on the site itself. The reader should note that any imagery presented here is specifically designed to draw in the non-technical audience, relying on bright colors and cartooning to accomplish the task. A reduced sulfur schematic is displayed as a preliminary example in Figure 1.
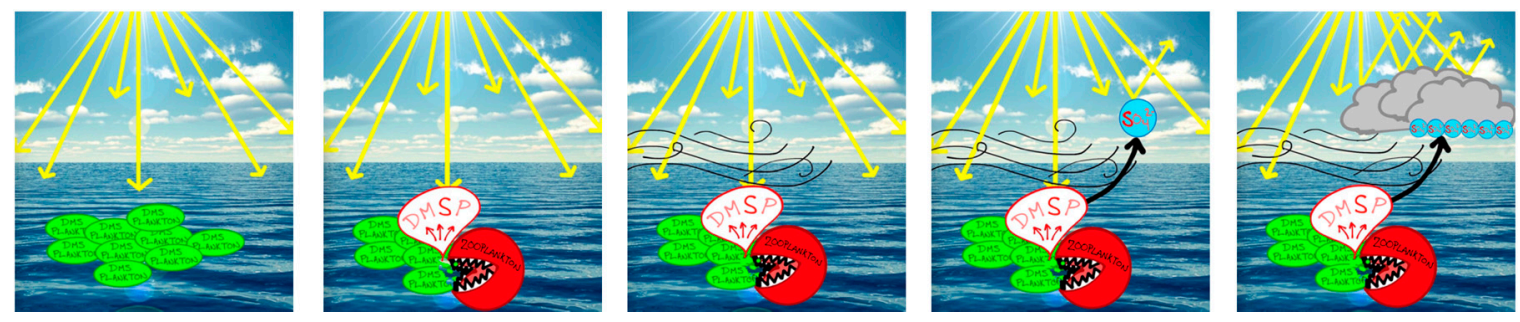

Figure 1. Selected images used on the website to illustrate aspects of the DMS cloud-albedo feedback. 


\subsection{DMS Cloud-Albedo Feedback}

Dimethyl sulfide (DMS, $\mathrm{CH}_{3} \mathrm{SCH}_{3}$ ) is a volatile compound containing a central, reduced sulfur atom which can increase cloud droplet number concentration, albedo, and lifetime when it is released to the atmosphere [6,7]. Since clouds are a dominant factor controlling the radiative balance of the planet, an understanding of primary aerosol emissions or trace gases like DMS, their contemporary budget, and pattern evolution due to climate change may be of extreme importance. DMS is best known as the protagonist sulfur carrier of the CLAW hypothesis (Charlson, Lovelock, Andreae, and Warren). In 1987, the authors of CLAW noted that DMS should control a feedback loop through marine stratus clouds and that this could act to reduce effects of global warming [7]. The strength and direction of the effect could not be specified at the time but there was speculation that a net, global marine thermostat might be involved. Since publication of the seminal CLAW work, environmental scientists have regularly re-studied DMS cycling and the details of its potential feedback channels, in repeated attempts to quantify the issue. Some have recently begun to raise serious doubts as to whether the DMS flux will indeed act to mitigate consequences of climate change. More detailed model results suggest the effect may, in fact, turn out to be positive, amplifying anthropogenic warming of the planet $[2,8]$.

\subsubsection{Air-Sea Exchange and Oxidation}

DMS is oxidized once released into the atmosphere. The reaction set is complex and produces several products, consisting of sulfur dioxide $\left(\mathrm{SO}_{2}\right)$, minor concentrations of methanesulfonic acid (MSA), carbonyl sulphide (COS) which controls the sulfur budget in the stratosphere, and several other compounds at negligible concentration. The $\mathrm{SO}_{2}$ then reacts with various $\mathrm{HOx}$ oxidants leading ultimately to the formation of sulfate aerosol particles $\left(\mathrm{SO}_{4}{ }^{2-}\right)[8,9]$. Production of $\mathrm{SO}_{4}{ }^{2-}$ is key to the influence DMS has on the planetary radiative budget, since the acid aerosol directly scatters incoming solar radiation, and furthermore goes on to add to the number of a cloud condensation nuclei (CCN) [10].

$\mathrm{CCN}$ are the prerequisite for cloud formation, and in some cases, DMS can increase the concentration of cloud condensation nuclei through changes in particle size and solubility [11]. An increase in the abundance of $\mathrm{CCN}$ shifts cloud structure toward smaller water droplets, increasing both their concentration and total surface area. Albedo responds directly to the latter through scattering theory. Particularly in the case of marine stratus, greater reflectivity and longer cloud lifetimes associated with a droplet spectrum dominated by smaller sizes influences net incoming solar radiation and overall hydrological cycling [10]. Thus, control of the global radiative flux can be closely related to sea-air transfer of DMS [8]. Although this paper describes the role dimethyl sulfide may play within the climate system, it is worth noting the net effect of the compound is still uncertain. The scientific community now accepts the influence ESN have as a CCN, yet further investigations are needed to determine the total impact of the DMS mBGC feedback [12].

\subsubsection{Sulfur Sources}

In the northern hemisphere, the sulfur cycle is dominated by anthropogenic inputs, while natural DMS production comprises most emissions occurring south of the equator. Through the burning of coal and oil, humans emit between $60-100 \mathrm{Tg}(\mathrm{S})$ into the atmosphere each year $[7,10]$. While this contribution accounts for most of the atmospheric trace elemental budget, the sulfur atoms tend to be short lived since sulfate is inherently involatile. Furthermore, it constitutes the primary cause of acid rain and most industries worldwide are working to remove all sulfur content from coal burning plumes. In any case, it is likely that coal will make a much smaller contribution to the global energy footprint in future scenarios [13].

DMS is produced naturally from several geochemical source types including fumaroles, biomass burning, volcanoes, and the aforementioned global phytoplankton. The overall emission budget for 
the molecule totals $25-80 \mathrm{Tg}(\mathrm{S})$ [10]. Marine ecosystems contribute $50-60 \%$ of total natural production, and they dominate the net sulfur cycle of the southern hemisphere [6]. It is important to mention that cell internal production and content are highly variable from one biological class to another. Different types of phytoplankton may exhibit vastly divergent production rates, and even within a species, dimethyl sulfide emission can vary strongly with environmental conditions. Nutrient, osmotic, and cryological stresses all lead to increases. Per the standard Linnaean system, classes such as Cyanophyceae (cyanobacteria) and Bacillariophyceae (diatoms) produce very little DMS [14]. In fact, model emissions are typically set to zero for these organisms. Specifically, the paper at hand focuses on two types of cyanobacteria, Synechococcus and Prochlorococcus, since they are abundant in most ocean systems and play an import role in climate change (discussed further in Section 2.1.5). Prochlorococcus is normally found within the top $150 \mathrm{~m}$ of the ocean but cell counts decline significantly in waters less than $15^{\circ} \mathrm{C}$. This restriction results in a favored habitat range of $40^{\circ} \mathrm{N}$ to $40^{\circ} \mathrm{S}$ with its peak located near the equator. Synechococcus has a wider and more shoal distribution than its cousin but again latitude limits are about $40^{\circ}$. A notable difference between the two cyanobacterial types is that Synechococcus can, in fact, survive down to the freezing point so that it can penetrate Arctic waters [15].

Marine Dinophyceae (dinoflagellates) and Prymnesiophyceae (the latter includes coccolithophores) produce most of the DMS emitted from the ocean [14]. These two classes consist entirely of medium-sized, eukaryotic phytoplankton and in general they possess the ability to synthesize a wide variety of reduced sulfur compounds. Yet only a few species are responsible for the majority of marine emissions. This results from a combination of their ability to generate the most appropriate reduced precursors internally, plus a tendency toward intense large-scale blooms. The prymnesiophyte Phaeocystis and well known coccolithophorid Emiliania huxleyi (EHUX) offer primary examples. Since DMS is relatively volatile (gaseous), it can be efficiently transferred from the vicinity of blooms from these planktonic classes upward into the atmosphere [6].

Phaeocystis is found in both temperate and polar waters, and it is best known for a propensity to produce foam-like, floating colonies. The cells surround themselves and communicate with one another through the release of polymeric aminosugars [16]. Colony formation is partially responsible for the large (regional) scale of P. blooms. This prymnesiophyte is the strongest DMS contributor in the vast circumpolar Antarctic ecosystems. EHUX is more abundant in tropical and oligotrophic waters. In these oceanic regions, and in many other such areas, it contributes the highest rate of DMS production [14].

\subsubsection{Natural DMS Production}

DMS is a metabolic byproduct generated from the cell internal precursor compound dimethyl sulfoniopropionate, often abbreviated as DMSP [17]. This latter molecule is synthesized along intracellular amino acid sequences, and DMS is then spun off for a variety of physiological purposes. For example, it is involved in oxidant control within the cytoplasm and also in dealing with external stress issues already mentioned above [6]. Phytoplankton also release minor amounts of the DMSP precursor directly. This occurs partly as a deterrent against predation, but most is emitted simply as a result of various modes of cell disruption. Phytoplankton degrade with age (senesce), and they may also be broken open by grazing or viral lysis. Either before or during such events an enzyme termed DMSP lyase cleaves the compound, with DMS and the small organic solute acrylate resulting as products [6]. Although the enzyme chemical processes are now believed to be well understood, explanations for the original evolution of the DMSP channel remain hazy. A popular but rather general theory suggests that phytoplanktonic dimethyl sulfoniopropionate arose due to its wide range of capabilities to afford protection from extreme conditions. At some point in Earth's history, there may have been the need to survive prolonged exposure on beaches during low tide or high salinity experienced in open water during glacial epochs [7]. Antioxidant function would apply to any situation in which primary producers were required to remain close to the sea surface radiation source [18]. 


\subsubsection{Ocean Acidification}

Since the preindustrial era, a decrease of $0.1 \mathrm{pH}$ units has been observed in the typical global ocean acidity value. This trend is expected to intensify, reaching a total of $0.25-0.4$ units varying geographically by the end of the century [2]. Specialists believe this may have a direct effect on production of DMS since any individual phytoplanktonic species has an optimal $\mathrm{pH}$ range for growth and performing metabolic functions [19]. An increase in ocean acidity could cause shifts in ecological community structure. Both Phaeocystis and EHUX are among the sensitive organism types. Recent mesocosm studies and numerical simulations have determined that expected acidification is likely to result in a $12-24 \%$ decrease in global DMS production by end of century. However, exceptions are anticipated in regions which would begin to favor zooplankton and grazers. In such locations, increased predation can outweigh reduced abundance of Phaeocystis and EHUX, potentially resulting in greater release of DMS [2].

\subsubsection{Increase in Sea Surface Temperature}

By now it is well-established that as the concentration of atmospheric $\mathrm{CO}_{2}$ continues to rise, there will be a significant increase in sea surface temperature (SST). Because phytoplankton reside within water layers of the upper ocean, this change has dramatic implication for their competitive community structure. Influences on reduced sulfur comprise a fascinating and yet understudied set of indirect consequences.

Low temperatures are physiologically restrictive of phytoplanktonic growth, such that a rise in SST expands habitats at least at some fundamental level. Related shifts have already been observed at midlatitudes [15]. However, increased SST also implies stratification of the water column. This will reduce the upwelling of cold, nutrient-rich water parcels, favoring those autotrophic species preferring oligotrophic conditions [10].

Both nutrient limitation and habitat expansion factors have favored proliferation of the various picocyanobacteria. To date, there has been a 14\% increase in Synechococcus populations and a parallel $30 \%$ increase in Prochlorococcus, with the largest values recorded in the northern hemispheric gyres and along the equator. Not only do the picocyanobacteria fail to produce DMS, they also act as direct competitors for strong emitters. The ascendance of the prokaryotes thus represents a compound effect directed toward the marine reduced sulfur source [15].

Counterexamples may be identified under the extreme climatological state and conditions at high latitudes. Increases in both lower atmospheric and oceanic surface temperature lead to an ablation of ice cover in polar regions. Loss of the ice pack allows a greater amount of light to penetrate the ocean surface [2]. Increased SST and insolation reduce several modes of biological limitation upon the general phytoplanktonic biomass, causing increased growth with an expected rise in cell concentration. In the Southern Ocean, reduction of pack cover leads to a small rise in primary production at ice edges surrounding the Antarctic continent, and also a much larger increase near the northern extent of the cold ecosystems and water masses [8]. However, recent research suggests that effects of ocean acidification may outweigh any augmentations to primary production in circumpolar waters [2].

\subsubsection{Wind Strength}

In the IPCC AR5 report, both regional intensification and reduction of wind strength are predicted [20]. These changes will alter the rate of sea-air transfer for the total family of marine trace gases, including DMS. As discussed in Section 2.1.2, Phaeocystis and EHUX are the strongest contributors to oceanic DMS emission owing to their high cell internal sulfur content plus a propensity to large blooms. Effects, however, are nonlinear and strongly amplified since changing winds speed influence the rates of both release (via nutrient availability to individual cells) and transfer (via thinning of the interfacial laminar-barrier layer), for the sulfur gas relative to the mixed layer. In some high wind regions, an increase in the volatile reduced sulfur flux can outweigh a decrease in DMS producing 
phytoplankton [6]. Such arguments appear regularly in the literature and are probably all true, in part. But the reader should note the implicit assumption that vertical profiles are not altered by enhanced turbulence in the water column. One dimensional modeling of the situation is called for.

\subsection{Ice Chlorophyll Feedback}

During late spring and early summer at high latitudes, the sun rises well above the horizon after the long polar winter and there is an annually recurring ablation of sea ice. Melting proceeds from about 50-60 degrees and advances toward the poles. With a greater portion of the regional sea surface exposed to sunlight, phytoplankton blooms tend to follow the ice edge. The new microbial communities perform photosynthesis as expected, but conservation of energy dictates that ultimately there is a degradation of the absorbed incoming solar radiation to heat. This drives further melting of sea ice leading to a strong and understudied feedback loop through the biological component of the climate system [21].

Closely related groups of phytoplankton can survive on top of or within the pack, where they are traditionally referred to as ice algae. The ecosystems may also be termed "sympagic" or "epontic". Darkened layers of pigment arise throughout the solid column of material, and these act as additional sources of heat for melting. Plankton have been observed to bloom near the periphery, inside of the ice, and even on the upper interface due to the supply of nutrients provided by wave action or floe sinkage attributable to heavy snow loading [22]. The warmth of summer causes the blanket of snow to thin as a rule. This allows sunlight which might otherwise be attenuated to pass through, reaching a layer richly flooded with nutrients. At this top level, the additional warmth melts a horizon several centimeters thick, creating a slush parallel with the ocean surface. A "gap layer" supports an intensified food web inducing yet another mode of feedback [23]. But in fact, the highest growth rates are measured along the bottom of the pack. This observation is consistent with relatively warm temperatures, imparted by the contact with seawater and maintenance of high porosity. There is saturation by a rich, nearby nutrient supply from the bulk water column. Large openings allow phytoplankton to enter sea ice from below - they thus become the "ice algae" while seeking protection from predation [22,24].

Taken together, these aspects of biological activity around and within the marine ice field may lead to reflective coverage loss. Considering the high albedo of the ice, runaway regional climate effects have been discussed and they appear to be a real possibility [21]. There is clearly a need for serious deliberation regarding the implied, potential alterations to polar marine food chains, ocean circulation, and global climate in the general sense [25].

\section{Website Design}

Layout and design properties are fundamental to the success of a website in most cases. Given the complex nature of mBGC feedbacks and the non-scientific audience targeted, information must be presented in a clear and concise manner. To accomplish this, the site includes color images or videos on nearly every page in order to keep content continuously engaging. Explanations are provided with subtexts in footnote or glossary style but in a highly compact, bulleted form. Scientific terms were replaced with more accessible descriptions wherever possible, and these were carefully crafted for quick comprehension. For example, the rather technical oceanographic phrase "thermohaline circulation" was replaced with the combination "Earth's circulatory system" in several locations. To achieve a level of final refinement, students now beginning to build their careers within the political community were contacted via direct communication-usually email messaging. A common suggestion from the sample was this: descriptions should be kept succinct, including only the most immediate and relevant information. To this end, each page in the web site presents significant facts in bullet form while simultaneously providing links to additional details. The more interested viewer/reader is encouraged to dig deeper if he or she so desires.

The primary reference used when designing the website was Facebook. This social medium was selected for emphasis because it is reported that more than half of the target audience maintain 
accounts and check them daily [26]. Facebook's simple and clean layout offers users ease of navigation plus certain initial start-up advantages. This arrangement along with the color schemes, link format, and curved box framing were all adopted and adapted during construction of what is, in fact, a highly specialized and informational marine feedbacks site.

\subsection{Climate Change Background}

The first few pages displayed on the menu are entitled, and intended to function as, "general background for the user/viewer". This portion of the site includes three topics (as questions) which may be useful preliminarily. They can be thought of as learning tools relative to the many conceivable mBGC feedbacks. The pages present only limited, skeletal information. This is of course because there are numerous online resources already available if a user wishes to pursue them. Each page includes brief descriptions, and sometimes even short videos providing the most fundamental information quickly and in a personalized manner. Additional links are sprinkled liberally through the material. Details included on the background pages are sketched in Table 1.

Table 1. List of pages and content included within the background section.

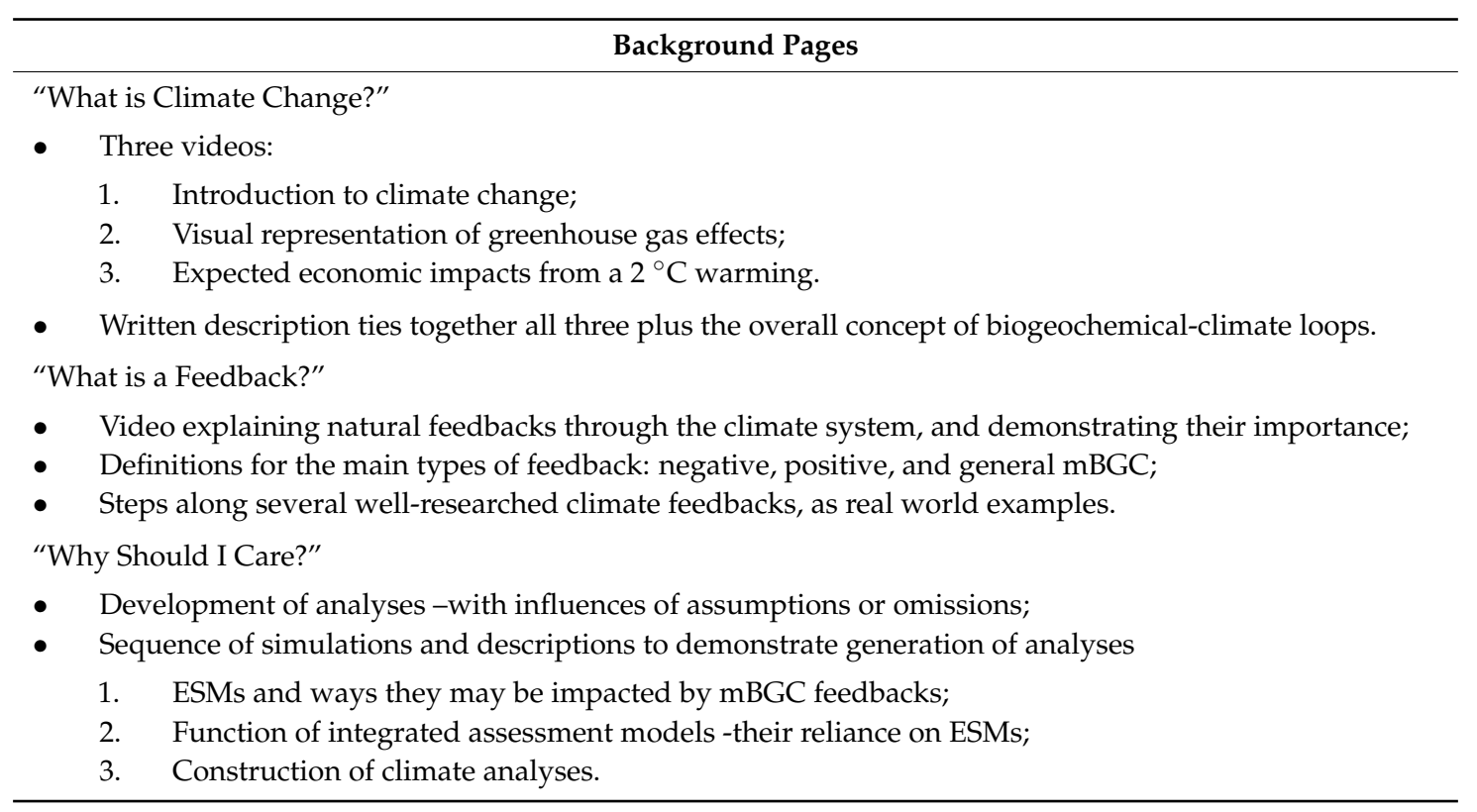

\subsection{Feedback Pages}

Pages in this section contain or refer to most of the technical information presented on the website. Both of the specially selected mBGC feedbacks are represented, and the formats are rendered intentionally similar in order to ensure the site is easy to navigate-continuity is maintained in this manner. As always, the web presentation strives for a colorful, striking appearance invoking stimulating images.

\subsubsection{Executive Summaries}

Summary material is offered at a high level and the goal in each case is to present all pertinent information in a single web site page reviewing a particular loop through the system. Naturally, most users sampled from our target audience will have only limited time available to them to learn about complex geochemical feedbacks through the climate system. This is regardless of their biogeochemical importance. Hence, both of the summaries contain only concise descriptions of the science and economics involved. 
The summary pages open respectively with the relevant major event sequence. Typically for a given feedback through the biological or chemical channels of the climate system, a researcher begins by simply listing the processes implied, perhaps with plus or minus signs indicating expected direction of influence. Some examples can be cited from the classic literature-the seminal CLAW presentation, or alternatively the rich (extremely complex) box and arrow diagrams in the Stefels et al. (2007) review of DMS sulfur physiology [6]. Here these traditional options are expanded, by amplifying and highlighting initiation and possible consequences in a web site mode. A sample outcome is shown in Figure 2. Every step is accompanied by a hand-crafted color image, in order to augment the potential for comprehension and participation. Economic impacts are positioned and described immediately below, listing real world monetary effects with both brief and extended explanations. Since data emanating from the economic and financial-technical community remain extremely preliminary, a formal analysis has not been conducted. However, the page attempts to allow for an individual level (qualitative) estimate of dollar-wise repercussions.

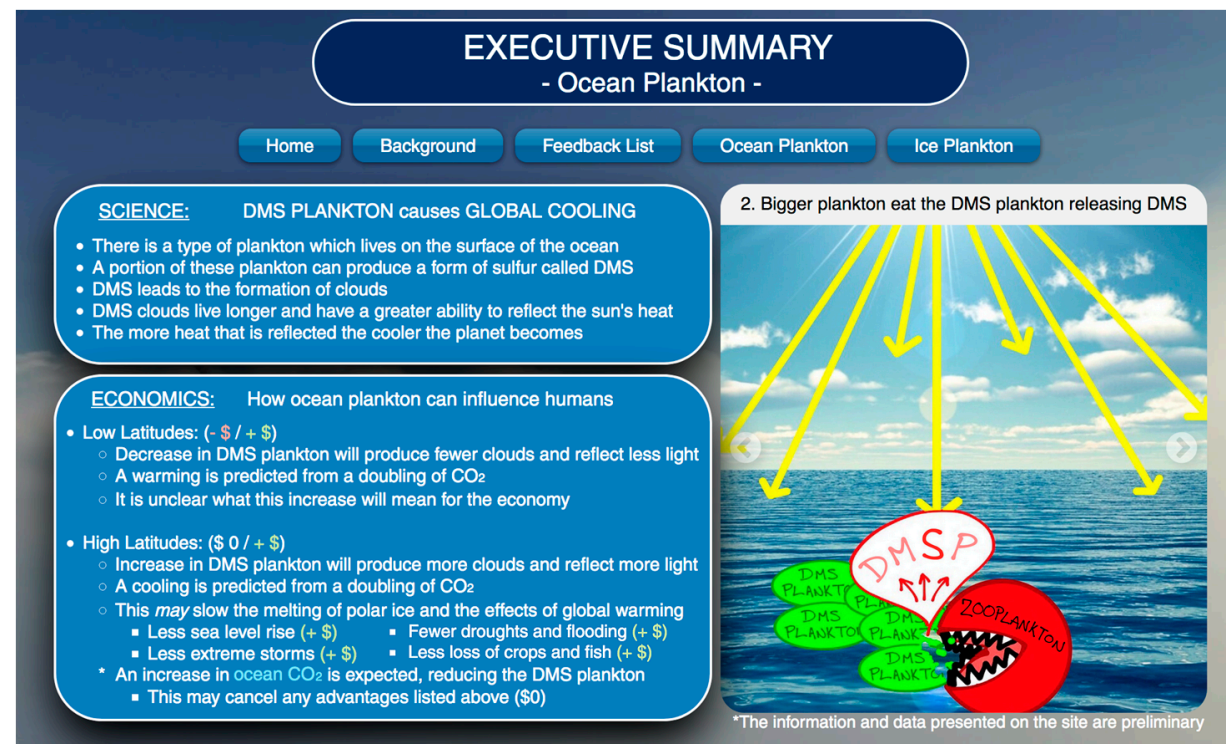

(a)

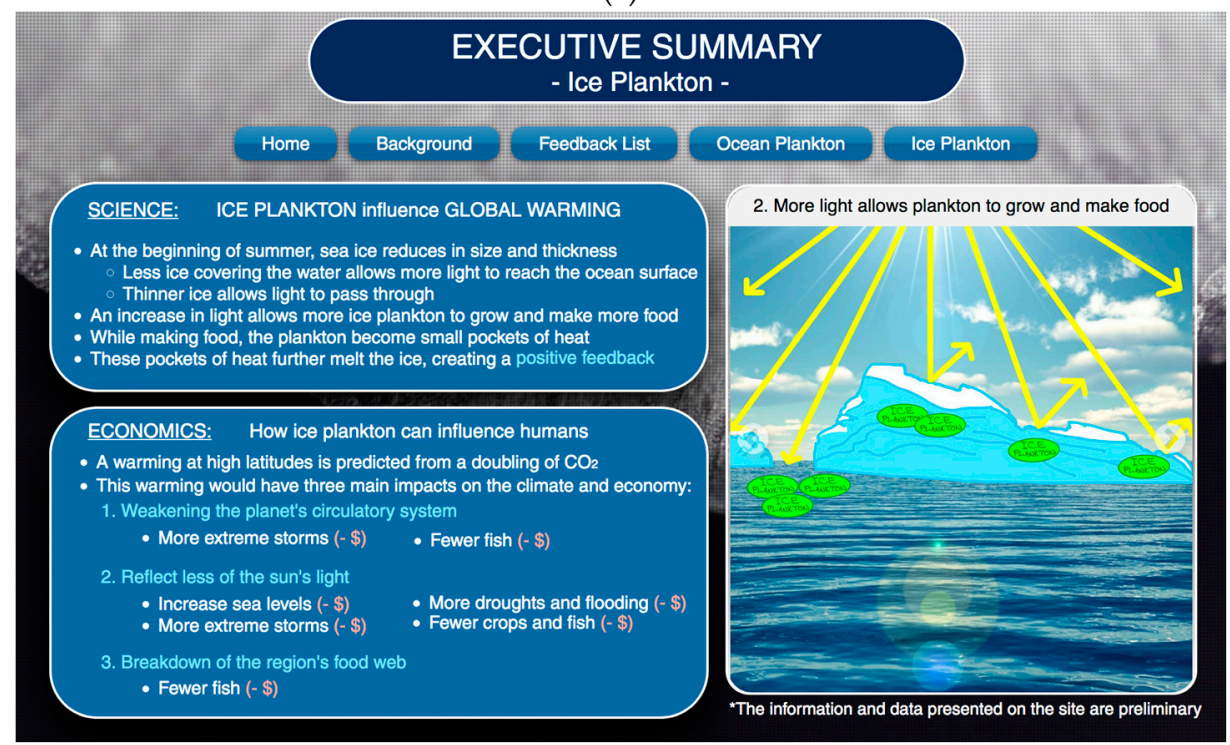

(b)

Figure 2. "Executive Summary" pages included on the website for the DMS cloud-albedo (a) and ice chlorophyll feedback (b). 


\subsubsection{Feedback Specific Background}

The background sections incorporated deeper into the site are specific of the two sample geochemical loops. They were designed to answer various peripheral questions that might arise, in the mind of the young viewer-policymaker while he or she is climbing the feedback learning curve. For the phytoplankton-cloud-albedo loop, this portion of the web material defines the biogeochemical role of dimethyl sulfide, tells the reader why it matters, and furthermore enumerates natural and anthropogenic sources of sulfur. The background page regarding global ice chlorophyll feedback first lays out the intense high latitude impacts of climate change, then the mechanisms by which plankton enter the interior of the pack. This area also touches upon several significant differences between the Arctic and Antarctic geochemical situations. For example, the Southern Ocean is dominated by thin first-year ice (seasonal) whereas northern polar waters are populated with thick multiyear ice (older than 1 year) $[27,28]$.

\subsubsection{Feedback Specific Steps}

Next, a series of web images is introduced constituting the true heart of the information site. A slideshow format is called upon to provide in-depth descriptions for each step in the two sample sequences. Multiple examples are offered to the viewer in each case, but the overall strategy remains quick and direct. The DMS cloud-albedo feedback subcomponent begins by itemizing, from a popular but biologically rigorous perspective, the multiple classes of phytoplankton producing the gas. Or in some cases, the opposite effect should be stressed; cyanobacteria contribute to the extreme global complexity of the situation by failing to generate any reduced sulfur at all. This of course concerns deep-time (Darwinian) evolutionary principles beyond the scope of the present work. The prokaryotes are distinct in this crucial biogeochemical aspect. Each autotrophic type is associated with a link leading users to a short list of basic information on distribution, habitat, and nutrient limitations. The slides demonstrate pathways by which DMS is released from phytoplankton. They also familiarize the viewer with photochemical reactions that transform sulfide to sulfate in the lower atmosphere.

The ice chlorophyll feedback page uses an image of the pack as the backdrop, and four crucial links are developed: for simplicity, these are referred to as the "outside, top, middle, and bottom" of the planetary marine cryospheric system. Directly beside the picture, a list of possible consequences from the net ice pigment feedback is included. For example, emphasis is placed on the necessity for, and the inevitability of, algal pigments acting as absorbers of incoming solar energy. It is shown that they go on to mediate the redistribution as heat. Since the cycle has four different pathways, the site is careful to segregate them conceptually. It was decided that the most comprehensive method for presenting the information to a potential viewer was to separate each channel into its individual sequences. Users can click on various permutations and walk themselves through any and every step. The goal here is to tour the intricacies of a dominant global biogeochemical sequence in an intimate, virtual manner.

\subsubsection{Climate Change \& Future Research}

Nearing the end of the web site experience, three significant impacts that climate change may be holding in store are examined more closely, relative to the DMS cloud-albedo connection. Attention is called to changes in global wind patterns, atmospheric carbon dioxide levels, and the surface ocean temperature distribution. Respectively the community is investigating whether these are likely to (1) alter dimethyl sulfide sea-air transfer rates; (2) destabilize the external hard parts of organisms such as the coccolithophores through acidification of surface waters; and (3) reduce nutrient supplies, and thus DMS producing marine biota, through stratification of the water column $[2,6]$. Each effect is described in terms of initiation, planktonic response, and possible large scale consequences. The approach is meant to relay the most important bits of information quickly and efficiently. Figure 3 is merely a snapshot example. Each individual impact from the figure offers further web based links, directing the viewer to in-depth explanations of the changes involved plus additional illustrations. 


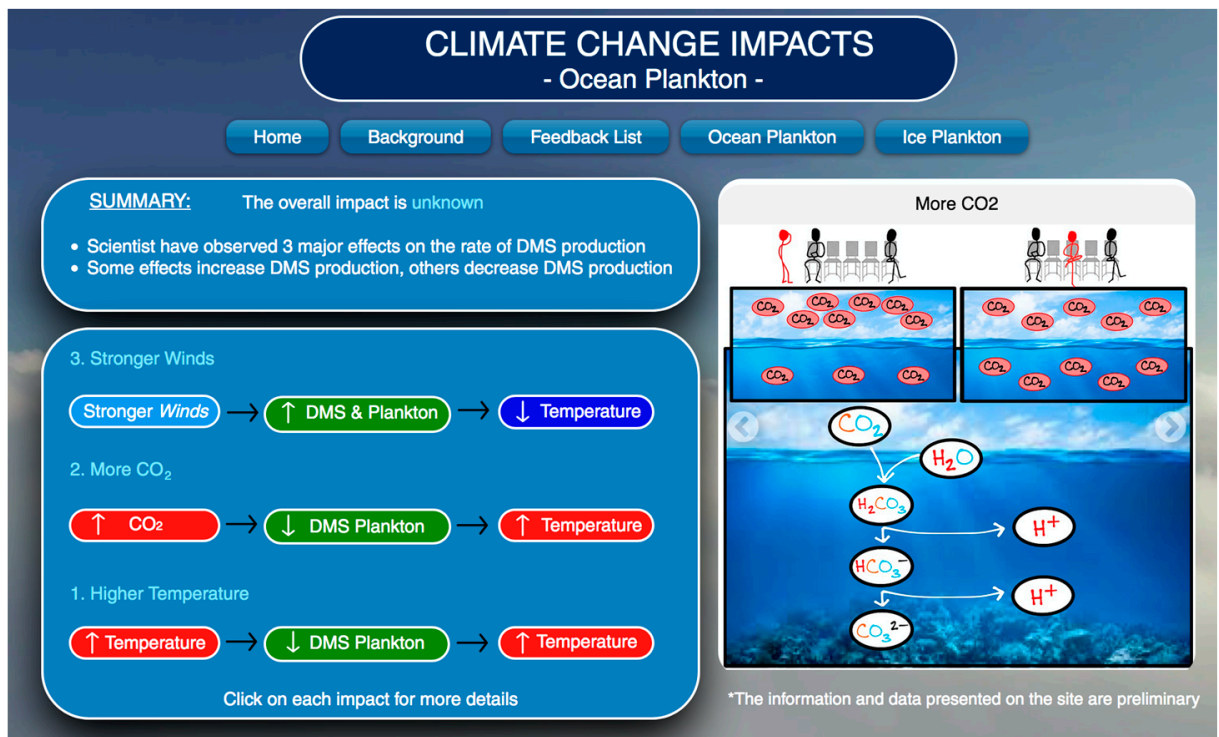

(a)

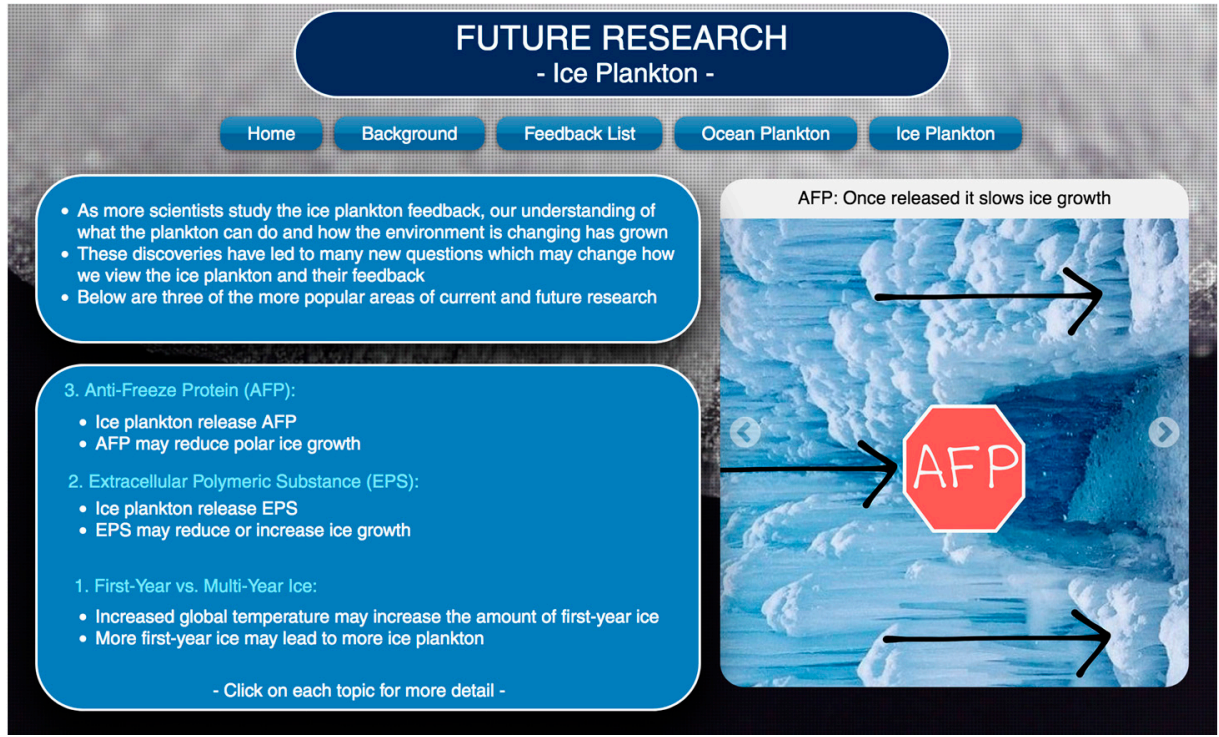

(b)

Figure 3. The "Climate Change Impacts" page for the DMS cloud-albedo feedback (a) and the "Future Research" page for the ice chlorophyll feedback (b) taken directly from the website. The climate change impact image includes a representation of a stick figure deciding where to sit. On the website, this illustration is used to demonstrate that both nature and a person choosing a seat will naturally spread out. This parallel is used to explain the scientific concept of diffusion. The future research image visualizes expansion of ice from the left to right side of the picture. However, the exudate-AFP- infers with the growth.

For the moment, the analogous page regarding ice chlorophyll feedback mechanisms has been omitted from the site. A pack-to-pigments impact image is currently in the design phase under the living-document philosophy of the overall project and should make its appearance at some point in the near term. Coloration of the pack may, in fact, turn out to be more important to climate change amplification than the aerosol precursor gases, given the brightness and bipolar extent of the sea ice system. However, it must be admitted that international research has been delayed in this area since high latitude warming is building so rapidly that it is difficult to quantify [21-25]. As an alternative, the website briefly discusses several key areas which may be relevant for future 
study. The biopolymeric chemistry of organic surfactants is featured here. It is likely that antifreeze proteins (exudates) are exerting unexpected influence on brine-ice interface structure along with its freeze-melt thermochemistry [29]. Saccharide gels may divert or even block fluid flow through the internal channel structure.

\section{Quality Assurance}

\subsection{Alpha Launch}

Scott Elliott of Los Alamos National Laboratory earth system modeling is a veteran investigator of biogeochemical feedback loops within the climate system. He has published numerous articles on both of the themes chosen for demonstration here. Throughout the project, Elliott provided guidance regarding the detailed mechanism steps and navigation of what has become over the decades an expanded literature. As a first test for the website, Elliott reviewed each page as it was completed ensuring accuracy of the primary technical information.

\subsection{Beta Launch:}

After the site was complete and had passed the assigned alpha tests, it was sent to the community to be reviewed by sources outside the primary institutions. Assessment and input were sought from prospective members of the target audience and their peers. E-mails were distributed to a range of groups to obtain responses from a variety of professional and young-career backgrounds, for example, students studying political science, fellow members of the climate science discipline, and peers who held no affiliation with either curriculum. In each of the messages distributed at this stage, several representative pages from the website were attached as samples of strategy, the description style, and general format adopted to organize the scientific information. Participants were asked to read these pages attentively, and then complete a survey requesting their thoughts and gauging their reactions. This input was closely considered, and any necessary updates to the material were made.

Once all changes had been completed, the evolving and improving site was sent to several experienced participants in the climate science process for a final check on communication techniques, and perhaps more importantly, for quality control and accuracy scanning. A list of individuals participating in this stage of the beta launch can be found in Table 2.

Table 2. Final reviewers during beta launch, with their associated organizations.

\begin{tabular}{|c|c|}
\hline $\begin{array}{l}\text { Scripps Institution of Oceanography } \\
\text { - } \quad \text { Lynn Russell; } \\
\text { - } \quad \text { Ellie Farahani; } \\
\text { - } \quad \text { Kate Ricke. }\end{array}$ & $\begin{array}{l}\text { Pacific Northwest National Laboratory } \\
\text { - Susannah Burrows } \\
\text { Joint Global Change Research Institute } \\
\text { - Corinne Hartin }\end{array}$ \\
\hline
\end{tabular}

\section{Marketing}

\subsection{Wix Promotional Tools}

An early marketing effort was thought to be especially important during the launch of the climate feedbacks site. Wix.com had been the main design platform, and so a final step was to take advantage of certain promotional features provided with the build tool. When the individual comments mentioned above had been thoroughly assimilated, layout and function were reviewed throughout the site under platform-level guidance. Valuable suggestions became apparent for potential improvement. For example, Wix enumerated the steps required to personalize URL names relative to each page. An overall description was generated for publication on Google. Lastly, research keywords were linked in for the website in order to increase traffic from global online searches. 


\subsection{Facebook Advertisement}

An additional marketing strategy adopted was the purchase of advertising rights to endorse on Facebook. A simple poster-type image was assembled covering the entire scope of the project, as shown in Figure 4. Certain logical, demographic, and interest groups were selected as targets for this particular advertisement. Generalized demographics were considered including level of education, field of study at the undergraduate and graduate stages, plus personal data such as political affiliation or job title. The promotion will run on Facebook throughout the next year and is expected to reach 500-2500 users per day. Reports from any positive outcomes or otherwise may be added within the ongoing, living document framework.

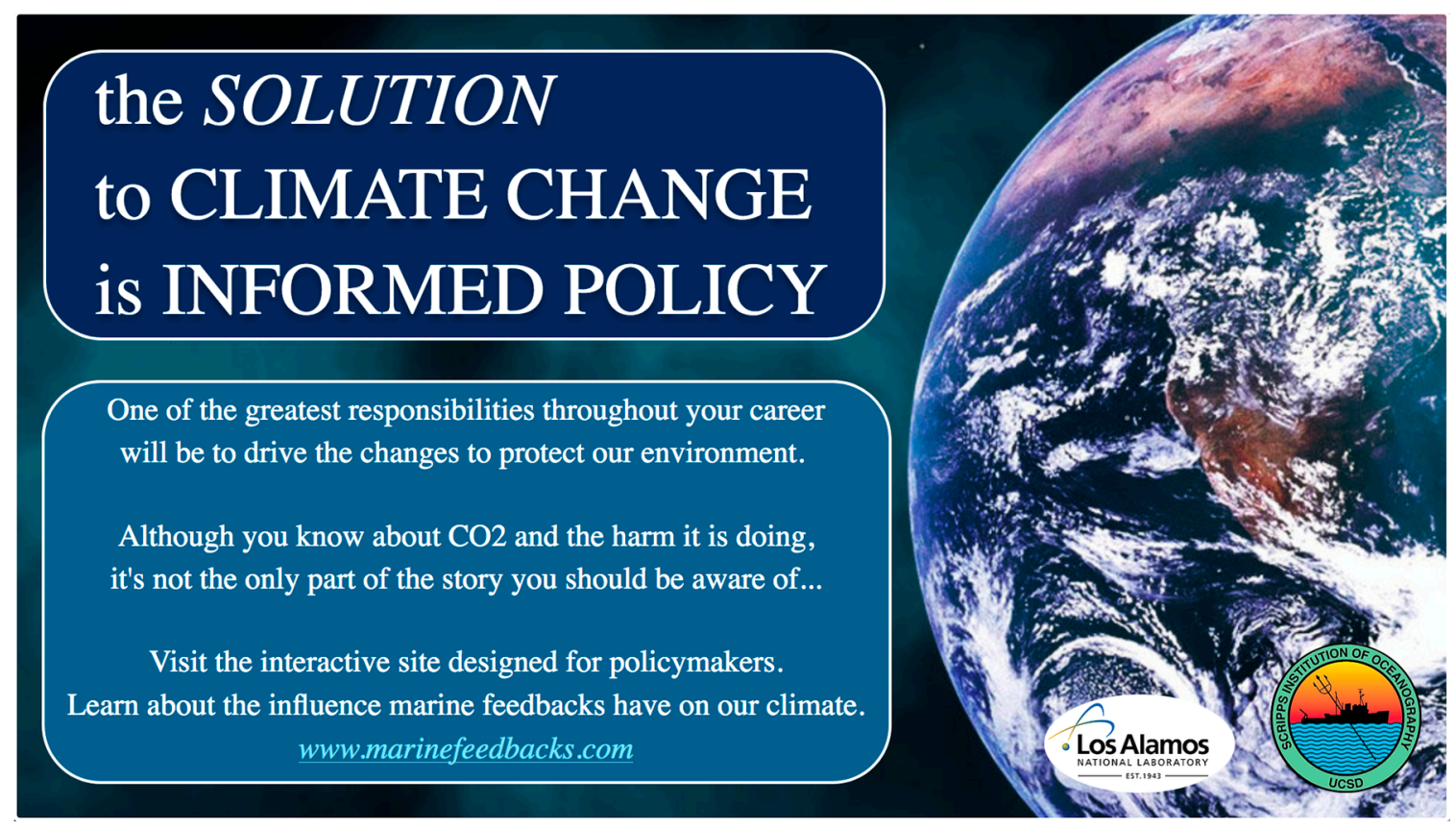

Figure 4. The advertisement used to promote the website on Facebook.com.

\subsection{University Networking}

The primary method of marketing employed here was direct contact with student-run democratic organizations. E-mails were sent to top universities around Washington D.C. in addition to the top 50 political science universities distributed domestically. Each message conveyed the importance of the information included through the various pages/links, and each reiterated the ultimate goal of the website (see above). Several groups provided access to their established student networks, and often the connections were university-wide in scale. With help from such organizations, the site was further promoted to specific college communities. Currently the campuses Harvard, Georgetown, the University of California-Los Angeles, the University of Virginia, and the University of California-Riverside have all agreed to assist with dissemination of the website. Effort is ongoing to accumulate further academic endorsements.

\section{A Living Document}

The website is designed to be a living document, which implies (1) the current version is intended to be usable and useful but not final; (2) authors of the website will encourage, vet, and accept relevant additions into the foreseeable future; (3) there will be a dedicated effort to facilitate additions. This stance allows for continual development and updates of the material, as more interested parties find the information then have their own ideas for unique contributions. 
Adopting the "Living Document" position should enable indefinite refinements to be incorporated into the framework. For example, it is hoped that international experts will be aware of feedback loops through the system involving the marine aerosol -but taking the community well beyond sulfur chemistry of the CLAW hypothesis. It seems plausible that strong climate switches will be discovered among rich interactions between organic surfactants residing at the global ocean-atmosphere interface. Wave driven bubble formation and breakage drive salt-spray production, but are controlled largely by organic chemistry so that potential examples are available $[5,30]$. Coloration noted inside the sea ice system necessarily implies the presence of detrital organic macromolecules in brine channels. These are likely to affect ice rheology and thermodynamics -proteins are known to function as antifreeze agents [29].

Keeping the web site "alive" also demonstrates an overall dedication to remain current at an empirical level. Multiple ship and aircraft based measurement campaigns augment the community's biogeochemistry database every year [31]. This research tends to be global in its geophysical scope and internationally distributed. Understanding of the complex climate feedback system must be updated accordingly. A flexible site can follow the instrumental and field developments faithfully.

Such continuing status should allow for refinements to the existing information, and for incorporation of additional mBGC feedbacks as required. Depending on the level of traffic and attention received over the next few months to one year or so, new biogeochemical channels will be added to the site using the techniques and formatting introduced here for DMS cloud-albedo and ice chlorophyll cycling.

\section{Summary and Conclusions}

The project described in the present work constitutes a first step toward resolving a classic disconnect at the science-to-policy intersection. A user-friendly, highly pedagogical mechanism is developed providing for outreach to a new generation of policy makers. Background and educational materials are organized as a web-based vehicle, in which several representative marine biogeochemical feedbacks are illustrated along with their influence on climate and systems model analyses. The technique acts as a bridge between the realms of climate science and environmental policy. Resources gathered and introduced are filtered to account for the limited amount of time and energy most young decision makers will have available to devote to climate studies. A channel is opened by which expert scientists may communicate crucial but complex topics to their neighbors across the community, in a thoughtful but engaging way. The intent is to catalyze the formulation of advanced and better-informed climate policies. Decisions should naturally be allowed to follow from an enhanced understanding of the complex global climate system.

The web device documented in this paper along with tests and samples can be found at the appropriately named site "Marinefeedbacks.com". The pages contained include fundamental information about global warming itself, natural feedbacks in the general sense, and ultimately specific examples of (1) marine reduced sulfur-to-global cloud albedo relationships, plus (2) internal heating of the sea ice medium due to an inherent chlorophyll content. Executive summaries, background information, and event sequences are outlined for each of the example mBGC feedbacks. Furthermore, major climate change impacts or lists of several future research topics are referenced in each case. Options are maintained for living-document style expansion of the approach. The site is currently advertised on Facebook, and it is beginning to diffuse through several university student democratic organizations with the possibility for a cultural multiplier effect to take hold.

During the website development process, a not-unexpected series of computational challenges was experienced. The information had to be tailored through multiple revisions, based on input received from preliminary reviewers during the beta launch. Most of the edits involved improvement to format and function. Several comments focused on the nature of preliminary understanding and data for mBGC feedbacks. All were considered faithfully as the site approached its true release. One iteration of the material incorporated quantitative data deriving from published estimates, gathered from experts 
in the various subdisciplines of Earth System Science. A particularly incisive suggestion stressed the risks of providing uncertain data to the non-scientific audience. However, it was ultimately decided that this is in fact precisely the reason for embarking on a pedagogical effort and so the information was retained. The site is constructed with the belief that errors in the climate and system simulation process are an undeniable part of the story, historically and moving into the future. Their potential must be recognized by the policy industry and a thorough explanation can only help users, exposing them to the intricacy and importance of mBGC feedbacks. Ultimately, historically and inevitably when studying a complex system surprises happen and can necessarily damage credibility, but a free and open discussion of the complexity benefits all.

A related, additional comment focused on the importance of accurately portraying the state of the (systems modeling) art. This reviewer felt that the site must convey the current level of understanding for mBGC feedbacks. In response, each web page clearly states the following in some way, shape or form -certain results drawn upon reflect a high degree of expert confidence, while others are more exploratory and require further research. However, the point is just this-the international policy community must be respected with the full spectrum of expert information as it becomes available. Laboratory, field and theoretical research will continue to refine our understanding in all cases, and likely indefinitely.

Acknowledgments: Author Z.M. thanks the Scripps Institution of Oceanography Climate Policy program and the U.S. Department of Energy OBER Feedbacks/Benchmarking project for their strong and steady support.

Conflicts of Interest: The author declares no conflict of interest.

\section{References}

1. Longhurst, A. Ecological Geography of the Sea, 1st ed.; Academic Press: San Diego, CA, USA, 1998; pp. 154-196.

2. Six, K.D.; Kloster, S.; Ilyina, T.; Archer, S.D.; Zhang, K.; Maier-Reimer, E. Global warming amplified by reduced sulphur fluxes as a result of ocean acidification. Nat. Clim. Chang. 2013, 3, 975-978. [CrossRef]

3. Van Etten, S.; Pressley, M.; McInerney, D.M.; Liem, A.D. College seniors' theory of their academic motivation. J. Educ. Psychol. 2008, 100, 812-828. [CrossRef]

4. Elliott, S.; Burrows, S.M.; Deal, C.; Liu, X.; Long, M.; Ogunro, O.; Russell, L.M.; Wingenter, O. Prospects for simulating macromolecular surfactant chemistry at the ocean-atmosphere boundary. Environ. Res. Lett. 2014, 9, 64012. [CrossRef]

5. Burrows, S.M.; Ogunro, O.; Frossard, A.A.; Russell, L.M.; Rasch, P.J.; Elliott, S.M. A physically based framework for modeling the organic fractionation of sea spray aerosol from bubble film Langmuir equilibria. Atmos. Chem. Phys. 2014, 14, 13601-13629. [CrossRef]

6. Stefels, J.; Steinke, M.; Turner, S.; Malin, G.; Belviso, S. Environmental constraints on the production and removal of the climatically active gas dimethylsulphide (DMS) and implications for ecosystem modeling. Biogeochemistry 2007, 83, 245-275. [CrossRef]

7. Charlson, R.J.; Lovelock, J.E.; Andreaei, M.O.; Warren, S.G. Oceanic phytoplankton, atmospheric sulphur, cloud. Nature 1987, 326, 655-661. [CrossRef]

8. Schwinger, J.; Tjiputra, J.; Goris, N.; Six, K.; Kirkevåg, A.; Seland, Ø.; Heinze, C.; Ilyina, T. Amplification of global warming through $\mathrm{pH}$-dependence of DMS-production simulated with a fully coupled Earth system model. Biogeosci. Discuss. 2017, 20,1-26. [CrossRef]

9. Brühl, C.; Lelieveld, J.; Crutzen, P.J.; Tost, H. The role of carbonyl sulphide as a source of stratospheric sulphate aerosol and its impact on climate. Atmosph. Chem. Phys. 2012, 12, 1239-1253. [CrossRef]

10. Kloster, S. DMS cycle in the ocean-atmosphere system and its response to anthropogenic perturbations. Rep. Earth Syst. Sci. 2006, 103, 1-103.

11. Quinn, P.K.; Bates, T.S. The case against climate regulation via oceanic phytoplankton sulphur emissions. Nature 2011, 480, 51-56. [CrossRef] [PubMed]

12. Andreae, M.O.; Crutzen, P.J. Atmospheric aerosols: Biogeochemical sources and role in atmospheric chemistry. Science 1997, 276, 1052-1058. [CrossRef] 
13. Liu, Y.; Zhang, J. Photochemical Oxidation Removal of $\mathrm{NO}$ and $\mathrm{SO}_{2}$ from Simulated Flue Gas of Coal-Fired Power Plants by Wet Scrubbing Using UV $/ \mathrm{H}_{2} \mathrm{O}_{2}$ Advanced Oxidation Process. Ind. Eng. Chem. Res. 2001, 50, 3836-3841. [CrossRef]

14. Keller, M.D. Dimethyl sulfide production and marine phytoplankton: The importance of species composition and cell size. Biol. Oceanogr. 1989, 6, 375-382.

15. Flombaum, P.; Gallegos, J.L.; Gordillo, R.; Rincón, J.; Zabala, L.L.; Jiao, N.; Karl, D.; Li, W.K.W.; Lomas, M.; Veneziano, D.; et al. Present and future global distributions of the marine cyanobacteria prochlorococcus and Synechococcus. Proc. Natl. Acad. Sci. USA 2013, 110, 9824-9829. [CrossRef] [PubMed]

16. Schoemann, V.; Becquevort, S.; Stefels, J.; Rousseau, V.; Lancelot, C. Phaeocystis blooms in the global ocean and their controlling mechanisms: A review. J. Sea Res. 2005, 53, 43-66. [CrossRef]

17. Andreae, M.O. Ocean-atmosphere interactions in the global biogeochemical sulfur cycle. Mar. Chem. 1990, 30, 1-29. [CrossRef]

18. Sunda, W.; Kieber, D.J.; Kiene, R.P.; Huntsman, S. An antioxidant function for DMSP and DMS in marine algae. Nature 2002, 418, 317-320. [CrossRef] [PubMed]

19. Dutkiewicz, S.; Morris, J.J.; Follows, M.J.; Scott, J.; Levitan, O.; Dyhrman, S.T.; Berman-Frank, I. Impact of ocean acidification on the structure of future phytoplankton communities. Nat. Clim. Chang. 2015, 5, 1002-1006. [CrossRef]

20. Stocker, T.F.; Qin, D.; Plattner, G.-K.; Tignor, M.; Allen, S.K.; Boschung, J.; Nauels, A.; Xia, Y.; Bex, V.; Midgley, P.M. Climate Change 2013: The Physical Science Basis. Contribution of Working Group I to the Fifth Assessment Report of the Intergovernmental Panel on Climate Change; Cambridge University Press: Cambridge, UK; New York, NY, USA, 2013; p. 1535.

21. Lengaigne, M.; Madec, G.; Bopp, L.; Menkes, C.; Aumont, O.; Cadule, P. Bio-physical feedbacks in the Arctic Ocean using an Earth system model. Geophys. Res. Lett. 2009, 36, 1-5. [CrossRef]

22. Zeebe, R.E.; Eicken, H.; Robinson, D.H.; Wolf-Gladrow, D.; Dieckmann, G.S. Modeling the heating and melting of sea ice through light absorption by microalgae. J. Geophys. Res. 1996, 101, 1163-1181. [CrossRef]

23. Ackley, S.F.; Lewis, M.J.; Fritsen, C.H.; Xie, H. Internal melting in Antarctic sea ice: Development of "gap layers". Geophys. Res. Lett. 2008, 35, 1-5. [CrossRef]

24. Ackley, S.F.; Sullivan, C.W. Physical controls on the development and characteristics of Antarctic sea ice biological communities-A review and synthesis. Deep Sea Res. Part I 1994, 41, 1583-1604. [CrossRef]

25. Ackley, S.F.; Buck, K.R.; Taguchi, S. Standing crop of algae in the sea ice of the Weddell Sea region. Deep Sea Res. Part A 1979, 26, 269-281. [CrossRef]

26. Pate, S.S.; Adams, M. The Influence of Social Networking Sites on Buying Behaviors of Millennials. Atl. Mark. J. 2013, 2, 92-109.

27. Arrigo, K.R. Phytoplankton dynamics within 37 Antarctic coastal polynya systems. J. Geophys. Res. 2003, 108, 3271. [CrossRef]

28. Lee, S.M.; Sohn, B.J.; Kim, S.J. Differentiating between first-year and multiyear sea ice in the Arctic using microwave-retrieved ice emissivities. J. Geophys. Res. 2017, 122, 5097-5112. [CrossRef]

29. Burrows, S.M.; Gobrogge, E.; Fu, L.; Link, K.; Elliott, S.M.; Wang, H.; Walker, R. OCEANFILMS-2: Representing coadsorption of saccharides in marine films and potential impacts on modeled marine aerosol chemistry. Geophys. Res. Lett. 2016, 43, 8306-8313. [CrossRef]

30. Krembs, C.; Eicken, H.; Deming, J.W. Exopolymer alteration of physical properties of sea ice and implications for ice habitability and biogeochemistry in a warmer Arctic. Proc. Natl. Acad. Sci. USA 2011, 108, 3653-3658. [CrossRef] [PubMed]

31. Frossard, A.A.; Russell, L.M.; Burrows, S.M.; Elliott, S.M.; Bates, T.S.; Quinn, P.K. Sources and composition of submicron organic mass in marine aerosol particles. J. Geophys. Res. Atmos. 2014, 119, 12977-13003. [CrossRef]

(C) 2018 by the author. Licensee MDPI, Basel, Switzerland. This article is an open access article distributed under the terms and conditions of the Creative Commons Attribution (CC BY) license (http:/ / creativecommons.org/licenses/by/4.0/). 